\title{
Communication as a Means of Development in a School with a High Percentage of Foreign Pupils ${ }^{1}$
}

\author{
Denisa Denglerová, Martina Kurowski, Radim Šíp \\ Masaryk University, Faculty of Education
}

\begin{abstract}
The text presented is a case study of one specific school in the Czech Republic, where many pupils with migrant backgrounds are concentrated. On the theoretical level, the study is based on experiential epistemology, which emphasizes interactions over the states and essences of actors or environments. This approach enables researchers to put the Bronfenbrenner's model of the ecological system in a broader context of Chicago School (interactions) and Palo Alto School (communication). Bronfenbrenner's concept of the mesosystem (in our case of the school) draw attention to the importance of communication and to specify three significant themes. The themes detect conditions that support and deepen the self/development of all actors involved (pupils, teachers, management, parents, etc.). In the methodological part, the themes have used as the frame for the frame analysis. In this way, the data collected in the school by observations, field notes, interviews are analysed. Although there are not many such schools like the one the authors research, they play an essential role in the integration of migrants into Czech society. That is the reason why the authors can discuss the outcomes of the study in a broader context and offer specific recommendations for state policies on the migrants' inclusion.
\end{abstract}

Keywords: experientialist epistemology, Bronfenbrenner's ecological model, mesosystem, communication, education, inclusion policy, migrants

In this paper we present the results of a case study undertaken at one government funded school for students aged 6-15 in the Czech Republic. This study focuses primarily on the first five years of education (age 6-11). Due to the school's history and location it has a high concentration (over 60\%) of students from different sociocultural backgrounds and with different mother tongues. ${ }^{2}$ This specificity influences the internal mechanisms and functions that affect the educational processes. Due to the breadth of the data collected it is not possible to present all the findings in one paper, therefore we decided to focus primarily on communication and on the mechanisms and functions that facilitate communication within the school.

We derived the importance of communication from Bronfenbrenner's (1979) ecological systems theory. The essence of the environmental approach is an emphasis on interactions between actors within peculiar environment strata (micro/meso/

1 The study was supported by the Czech Science Foundation through the project Roads Towards 21st Century Inclusive School: An Ethnographic Approach (GA19-13038S).

2 In this paper, we are using the term foreigners or foreign pupils for migrants, immigrants, incomers, etc. By the term learner with a different first language, we mean all school-age learners whose mother tongue is not Czech. In the context of the school, this concerns mainly learners with foreign citizenship or learners with at least one parent who is a foreign national. 
macro-levels). By communication we do not just mean the exchange of information through language. We perceive communication in a broad sense, as an exchange of information as well as materials leading to a structuring or restructuring of the milieu in which actors live. Before we describe the theoretical background, it is important to understand the specific context of the school in terms of Czechia and the city where the school is located.

\section{The context}

The Czech Republic is seeing a steady increase in the number of foreign residents. In 1980s, the number of foreigners in Czechoslovakia was constant and showed a negative net migration rate. In 1990, just after the fall of Communism, the total percentage of foreigners in the country was a mere $0.3 \%$. Following the opening up of the Czech economy and entry to the EU in 2004, by 2015 the percentage had risen to $4.3 \%$, which is the same percentage recorded in countries such the Netherlands and Portugal. More recently figures have risen even more sharply. As of December 2018, there were a total of 566,931 foreigners in the Czech Republic, which is $7 \%$ more than at the end of $2017 .{ }^{3}$ Foreigners now make up approximately $5 \%$ of the total population of the Czech Republic.

The right to education is one of the fundamental human rights that belong to all children regardless of difference. Providing compulsory schooling for children with a migration background ${ }^{4}$ is part of Czech legislation and is in accordance with international agreements to which the Czech Republic is a signatory. This means that migrant children are entitled to the same basic education as Czech children because education is mandatory for everyone. However, the Czech education system leaves much to be desired when it comes to catering to the educational needs of foreign pupils and many features are lacking when compared to systems from abroad (Hamilton \& Moore, 2004, pp. 2-7). For example, there is no official language support to help with interpretation for parents, there are a lack of the teaching assistants and intercultural workers and there are minimal additional language courses available.

Due to structural conditions and historical circumstances, children of foreigners are concentrated in a few schools throughout the Czech Republic, usually in large cities. These schools are independent of each other and therefore each of them creates an entirely original mesosystem with different approaches to communication.

The city is located in one of the most important migrant destinations in the country. In 2018 it recorded 32,000 foreigners living there, most of whom were from countries outside of the EU. The largest groups of migrants were from Ukraine, Slovakia, Vietnam and Russia and this distribution corresponds with statistics at

3 Czech Statistical Office (2019). Data - number of foreigners. Available from: https: / www.czso .cz/csu/cizinci/4-ciz_pocet_cizincu\#cr

4 In the frame of the Czech law, most of these children are long term or permanent residents; they are not considered citizens of the Czech Republic. 
a national level. Foreigners are motivated to migrate to the Czech Republic mainly

by the job market and an open tertiary education system, which is not only of high quality but also affordable.

The school that we focused on is located in a city where 1,034 foreign pupils were enrolled in schools (age range 6-15) in 2017/18, which amounts to approximately $3 \%$ of all primary school pupils aged 6-11. The majority of foreign pupils (65\%) attending schools in the city are within the 6-11 range.

In 2018 the school had 214 pupils from foreign countries, which amounted to $67 \%$ of the total number of students. This situation is the product of several factors that culminated in close cooperation of the school mesosystem with other systems that directly influence the schooling of learners from foreign countries. In 2005 the number of children living in the school's locality or 'catchment area' began to decrease and the school was in danger of being closed down. Following negotiations with the Mayor of the city and the Education Department of the Regional Authority (which coordinates the schooling of children of foreign nationals), the principal was able to secure a grant from the Ministry of Education, Youth and Sports (henceforth the Ministry) to support the teaching of Czech to citizens of third countries. The school therefore began teaching children of foreigners regardless of the location of their home or whether they were in the school's 'catchment area'. Schools from other parts of the city then responded to the school accepting foreign pupils from outside of its 'catchment area'. "[T] should go there. They are recommending us, so that's OK." The school has been cooperating with the Regional Authority on teaching Czech to learners from third countries. ${ }^{5}$ It also collaborates with the Education Department of the City Hall and non-profit organisations. Cooperation with these institutions does not only revolve around learners with a different first language, but focuses on teaching all learners with specific learning needs, or on the implementation of cross-cutting themes of the school educational programme.

\section{Theoretical framework: Bronfenbrenner's human ecology theory and communication}

We are using Bronfenbrenner's (1979) ecological systems theory as the base for our theoretical framework. At the heart of this approach is the effort to find a research model that would allow a shifting of the focus from the actors (persons, institutions) to the interactions between them and especially to the quality of their transformation (their development). Ontologically speaking, this shift represents a broader paradigmatic shift from essentialism or objective realism to processualism or experientialist realism (Lakoff, 1987; Johnson, 2007). Experientialist realism enables us

5 We consider a third-country citizen to be a person who is not a citizen of the Czech Republic, nor any other EU member state, nor is the family member of a citizen of the Czech Republic or an EU member state. 
42 to concentrate on the relations and transactions amongst actors and between actors and their environment without the prejudices of objectivism. Objectivism favours states and essences and examines them as though these states and essences have not undergone constant change and reconstruction. On the contrary, experientialism assumes that everything is in continuous evolution and that states and essences are only temporary platforms that shape the time-limited situations in which the actors find themselves and act (Dewey, 1939; Dewey \& Bentley, 1949; Johnson 2007).

This paradigmatic change is beneficial for us for two reasons: Firstly, it is more suited in the nature of social science research, and secondly, it allows us to perceive communication as being central to interactions. Communication intensifies the interactions and possible changes and adaptations. In the concept of communication, we are inspired by the tradition of the Chicago School (Mead, Dewey, and their contemporary followers, e.g. M. Johnson and G. Lakoff). This tradition sees all interactions as events that gain meaning in communication through an exchange of symbols. Communication is primarily a social issue. In Dewey's words it is, contrary to animal actions, not "ego-centric" but "participative", allowing actions to be governed by the exchange of tokens. Symbols define events and enable the sharing of their meanings. Thanks to the control of actions by communication, we can change both the subsequent steps of the actors and their environment (Dewey, 1958, pp. 166-207). Therefore, communication "is a means of establishing cooperation, domination and order" (ibid., s. 202). Restoration of order creates dynamic homeostasis that enables actors to act deliberately and negotiate common goals and then achieve them.

If we wish to divert our research from examining the states and essences of the actors, institutions and environment, and instead emphasize the interactions, processes, and changes that affect the quality of development, we must seek new methodological tools. Bronfenbrenner's approach is one of the ways we can implement the introduced ontological base into a specific type of human sciences research. Although Bronfenbrenner does not directly refer to the ideas of the Chicago school, there are occasional references to Dewey's thoughts on education (e.g., Bronfenbrenner, 1979, p. 23; Hayes, O'Toole, \& Halpenny, 2017, p. 152). Nonetheless, his approach is in accord with the main ideas of the School. In the thoughts of the School, as well as in the Bronfenbrenner approach, interactions are a crucial concept. For example, primary dyads (the most straightforward interactions between two actors) and molar activities (conduct which is of such a nature that any development takes place during it - cf. ibid., pp. 45-48, 58-60), in the ecological approach, are the base of all other operations leading to development. The base is created neither by actors as such nor by settings, but by interactions. Interactions intensify communication amongst actors and re/construct roles they are required to play. Communication and roles influence their personalities. The quality of these factors enables or slows down their development. The quality of the interactions therefore strongly influences the possibilities in which the actors may develop. This is the reason why Bronfenbrenner concentrates primarily on interactions and not on essences, truths or fixed qualities. 
Systems of overlapping interactions are the basis of social platforms - the socalled settings. Settings are constructed via the activity of participants and depending on their location, they can constitute microsystems, mesosystems, exosystems, and macrosystems (Bronfenbrenner, 1979, pp. 22-27). Every activity, actor, or relationship is therefore nested in many levels. A pupil can be a member of microsystems - family, close friends, school clubs, etc, as well as mesosystems - school, peer groups, or the cultural communities from which the pupil's family comes. However the pupil is also indirectly affected by exosystems, e.g. a system of experts engaged in a dialogue in favour of or against inclusion, and even by the macrosystems of the educational, cultural and social policies of the host country or international legislation that pertains to the status of foreigners. The pupil's development is determined by the configuration of relationships at all levels.

The notion of meso-level is key to our study, as it best describes school as a specific organisation where most of the pupils' education takes place. Moreover, it has significance in more general terms, since the meso-level is where the greatest shifts in each participant's developmental potential occur. Bronfenbrenner primarily relates human development to a mesosystem (ibid., pp. 209-236). A mesosystem emerges where the molar activities of individuals and whole groups cross their boundaries into multisetting participation. This creates a new situation - a meso-level setting, which hosts participants who are also active in various micro-level settings. This new setting requires coordination of the original and the new roles, with communication between settings and a new quality of experience. The individual crosses the boundaries of microsystems and is forced to assume roles in a more complex arena. They must adjust to more indirect linkage. Indirect linkage means that new actors bring the horizons of their microsystems into other participants' field of operation and indirectly expose them to the demands of unfamiliar settings. Each pupil therefore brings into the classroom (microsystem) and school (mesosystem) the values, attitudes and habits that they acquired in the family, in various clubs, during telephone calls with grandparents, etc. And in this way, values, attitudes and habits are brought into the system of the school by teachers and other actors. This developmental niche is described in detail by Harkness and Super (2002, pp. 272-273). Intersetting communication becomes denser and creates a new, specific type of knowledge - intersetting knowledge (Bronfenbrenner, 1979, pp. 209-211).

A child's transition (Dockett, Perry, \& Kearney, 2012, pp. 59-60) from the original microsystem into the mesosystem progresses from primary socialisation towards secondary socialisation. This transition has a critical potential, in that there are two kinds of complications. The mesosystem is affected by microsystems, as actors who shape the mesosystem carry on to a higher level the habits and expectations that they acquired at a lower level. Within education, the values, attitudes and habits of families, social groups, peer groups and other microsystems enter the school environment and the school must respond to them constantly. However, the claims of the microsystems they place on their members can be questioned. Some determining values, attitudes and habits, which are crucial for the given microsystems, 
44 may conflict with the values, attitudes and habits of a mesosystem (e.g. the school). This complex situation places great demands on both the individual actors and the settings at all levels (micro/meso/macro-levels), making communication that much more important. The ecological principle operates on the basis of perpetual fine-tuning, or achieving a dynamic (homeostatic) equilibrium (Damasio, 2018).

The increase in the complexity of mesosystem situations in turn multiplies and complicates interactions and raises the difficulty of coping with any given situation. The mesosystem exposes individuals to unprecedented diversity and intensifies the requirements for understanding and managing diversity. This makes the mesosystem crucial for human development. Bronfenbrenner defines human development as follows:

The process through which the growing person acquires a more extended differentiated, and valid conception of the ecological environment, and becomes motivated and able to engage in activities that reveal the properties of, sustain, or restructure that environment at levels of similar or greater complexity in form and content. (Bronfenbrenner, 1979, p. 27)

This development has two-fold manifestations - in the perception of the situation and of the acting within it. A developing individual is able to perceive contexts that go beyond the boundaries of a certain situations and following a successful understanding of the situation, can act at various levels (micro, meso, and macro) with a greater complexity and success (cf. Bronfenbrenner, 1979, p. 28). For "situation" as a crucial term for the experientialist epistemology, compare Švec, Nehyba, Svojanovský et al. (2017, pp. 47-52).

Bronfenbrenner (1979, pp. 211-242) developed 17 hypotheses which determine the ideal conditions for an individual's development at the meso-level. He indicates that these hypotheses are derived from previously conducted investigations, based on which prescriptive definitions of processes were formulated. They are therefore definitions or hypotheses of sorts, which stipulate the conditions under which the development of each actor participating in the mesosystem progresses the best. This way of constructing an ideal model prompts researchers to employ abductive reasoning during their research. Besides other things, abduction means that researchers do not use the ideal model as a fixed measure of the right or wrong configuration of the real processes within a mesosystem. When they discover that some of the properties of the ideal model need to be modified, they will modify them.

We had to do such modification when moving from an idea of an operational language as a key term for this paper to an idea of a field of mutual understanding. By operating language, we meant a language in which we achieve, exclusively or at least dominantly, mutual understanding, and in which teaching takes place. We continue to work with this definition. However, we found that there are several operating languages in our ethnically, religiously, and nationally diverse school Czech, English, Ukrainian and Russian. These languages are switched according to situation. For instance, a teacher tries to teach in Czech, but if a learner fails 
to grasp a key piece of instruction even after several repetitions, she will briefly switch to English and then return back to Czech. Most of the time, the teachers use Czech to speak with the children, but when communicating with parents, they need to find another common language. The presence of several operating languages poses the question of how one can reach understanding while switching from one language to another or how it is possible to translate one language to another when few actors know both or more languages. This is why we needed to define a broader environment that would allow us to explain how to switch from one language to another while creating a common understanding. In this situation, we, as researchers, realized that we had to look for a common denominator, which, in addition to the operating languages, has other elements that allow translations from one language to another. Thus gradually, the idea of the field of mutual understanding began to emerge. Finally, we realized that this concept is more consistent with situational ontology and the epistemology of experientialist realism. (For more on this concept, see the following paragraphs.)

We chose those Bronfenbrenner's hypotheses which are relevant to the circumstances of educating learners with a different cultural and language background.

The developmental potential of settings in a mesosystem is enhanced when the demands placed on roles within the different settings are compatible and when the roles, activities, and dyads in which the developing person engages encourage the development of mutual trust, a positive orientation, goal consensus between settings, and an evolving balance of power in favour of the developing person. When there are structurally different settings in which the developing person participates in a variety of joint activities and primary dyads with others, particularly when the others are more mature or experienced. When the settings occur in cultural or subcultural contexts that are different from each other in terms of ethnicity, social class, religion, age group, or other background factors. When the system supports trans-contextual dyads ${ }^{6}$ that cross the boundaries of various settings. When there are so-called supportive links between one setting and others. ${ }^{7}$ When there are indirect links between settings that support the same goals as the supportive links. When two-way communication between settings occurs with ease, during which the inclusion of the family in the communications network is key. When, prior to entering a setting, the actors receive relevant information, when this information is continuously accessible in other settings, when this information is as personal as possible (face-to-face conversation, personal letter, telephone call, announcement).

We included one more element or hypothesis into this description of the meso-level, one which Bronfenbrenner's hypotheses, though implied, do not mention explicitly. From a certain level of interaction, the participants of individual

6 Bronfenbrenner's trans-contextual dyad is a system of interaction between at least two actors acting within one setting that enters into a new setting; e.g. friends who start school together, friends who emigrate together and apply for asylum together, etc.

7 A supportive link is such a link between settings that ensures that the same activities, their goal and focus, are supported within all the settings involved (cf. Ibid., p. 214). 
scenes cannot do without long-distance communication, ${ }^{8}$ and interactions that are coordinated and carried out in a field of mutual understanding. The results of our research show us how important it is to define a language/s in which all actors share a common understanding and can act meaningfully, intentionally, and in accord with other actors. Following the Chicago School tradition mentioned above and the Palo Alto School, we understand such a language/s more comprehensively as a complex field in which mutual understanding takes place. We are inspired by the work of Watzlawick and his colleagues. Moving the focus of our interest from the family as a field of understanding (Watzlawick, Beavin, \& Jackson, 1962, pp. 134-147) to the school as a more complex field, we enter an environment where understanding is more challenging to achieve. This field evaluates both the verbal and non-verbal components of the different languages and the characteristics of the environment in which interactions occur - such as properties of physical objects, negotiated standards, spoken or unspoken rules etc. The higher the number of different mother tongues or operating languages in a given milieu (in this case, our school), the more important environmental characteristics become.

In an ideal scenario, there would be an operating language that is understandable to all participants of the scene as well as scenes directly or indirectly linked with the central scene (in our case, the meso-level of a school). However, these circumstances cannot be met, even in a linguistically and culturally homogeneous class. There are so many differences amongst habits, ways of acting, expectations or values, which the actors bring from their microsystems (in our case, e.g. from their families or neighborhoods) and these factors affect the quality of the operating language, splitting it into several different forms, which need to be translated to be mutually intelligible. Therefore, one operating language is not a sufficient condition for the interactions to be of adequate quality and to lead to the successful development of all actors in the mesosystem. In such cases, it is necessary to create an environment in which all actors can translate and then understand different expectations and conduct. Those features of the environment that are not strictly tied to language and cultural heritage are essential in seeking translation and understanding. The material characteristics of the environment, the standards that the school presents and further negotiates, the principles and rules, the consequences of our actions, etc., become such a means of understanding. In the case of a multilingual and multicultural school or class, building such an environment is even more critical. In such classes, there may be a situation where there are more than one operating languages. For example, the teacher speaks to some of the pupils in Czech and to some in English and to some of the parents in another language). This type of situation can deepen cultural differences even more and therefore the existence of these elements in the environment, rules and norms is becoming crucial.

The availability of one operating language in the school is highly unlikely. This is why our research recognizes the key role of strategies that allow the school to re-

8 For more on the significance of long-distance communication in modern societies, see (Noiriel, 2012). 
spond to the need to communicate in cases where virtually no shared communication language is available. Strategies which enable several communication languages to overlap and facilitate information transfer. It is this respect for the role of a field of mutual understanding that we identify the following three research themes:

Theme 1 - Continuous communication as the central value of the school

Theme 2 - Communication as interactions amongst microsystem, mesosystem, and macrosystem

Theme 3 - The field of mutual understanding in relation to operating languages

\section{Methodological framework}

We decided to use a case study approach as the research strategy since the school we focused on has specific features which can help us understand the processes of inclusion of children with a migration background to the Czech education system (e.g. Yin, 2012, pp. 141-155). Based on Bronfenbrennner's approach, we can more easily demonstrate how the dynamics of interactions between microsystems and the mesosystem is going on. The obtained data was analysed using framework analysis. The use of framework analysis was based on the fact as researchers we are able to gather and sort in a meaningful way the collected data and subsequently articulate and map the phenomenon under investigation (Srivastava \& Thomson, 2009, pp. 75-76).

\subsection{The frame for analysis}

In the following paragraphs, we define the three themes that characterize the phenomenon. These themes were derived from the Bronfenbrenner's 17 hypotheses (Bronfenbrenner, 1979, pp. 211-242) and our concepts of the operating language and the field of mutual understanding which complement Bronfenbrenner. Focusing on the themes helps us to structure the phenomenon and focus on the data that articulates the phenomenon.

Theme 1 - continuous communication as the central value of the school. The central value of an ideal school is continuous communication. Communication focuses mainly on the sharing of information, articulating of personal, group, and institutional needs and goals, negotiating common goals, and negotiating joint activities to achieve those goals. This theme is articulated by questions such as: What value does the school ascribe to communication? What communication strategies can the school use to learn about the goals and needs of individuals and microsystems? What communication strategies does the school use and negotiate to articulate these goals and needs?

Theme 2 - Communication as interactions amongst microsystem, mesosystem, and macrosystem. Communication enables actors to achieve what Bronfenbrenner called multisetting participation. This means the ability to emerge from micro- 
48 systems to mesosystems and work in both without collisions. This ability is met by coordinating micro-level interests with meso-level interests. The majority of communication on the meso-level takes place over distance (via documents, rules, norms, email or postal correspondence) and quality of this remote communication facilitates indirect linkage with other parts of the system (microsystems, exosystems, macrosystem). Questions relevant to the restructuring of the second theme are, for example: In what ways does the school coordinate and balance the interests of microsystems and macrosystems? How does the school establish communication between microsystem settings? Are these techniques conducive to the participation of all individuals in joint activities in different settings? Are there any limitations in the microsystems that prevent pupils from joining in activities in different settings and what is the school doing to reduce these limitations?

Theme 3 - the field of mutual understanding in relation to operating languages. A crucial condition for the smooth flow of communication is the blending of different operating languages, which bond together all the settings that make up the mesosystem (directly or indirectly) and which make it easier for an individual to be engaged in the mesosystem's functioning. In order to make flexible use of operating languages, it is necessary to use other elements that are part of this field of understanding - the properties of physical objects, negotiated standards, spoken or unspoken rules etc. This theme is articulated by questions such as: What are the operating languages that are important for communication in the mesosystem? Are these languages available and usable in all settings at the micro-level and other meso-levels linked with the school? What strategies can the school use to remove barriers that prevent communication in all the given settings? How does it convey the requirements of the macrosystem to those actors who cannot access this information in the operating language?

\subsection{Methods of collecting data}

Our dataset consisted of notes taken during observations of 25 lessons in the autumn of 2018. We also conducted several interviews with the school principal, school counsellor and teachers of both primary and lower secondary level teachers (the 6-11 and 11-15 age groups). Lastly, we obtained a sample of information from focus groups with teachers across all years. The school psychologist was also present. In total, we obtained 320 minutes of sound recordings, whose detailed transcription underwent frame analysis, during which we were constantly reflecting upon each frame theme.

\section{Results}

We present the results in the order of three previously defined themes. 


\subsection{Continuous communication as the central value of the school}

The first area concerns general communication strategies that the institution employs internally as well as outwardly.

Communication becomes important even before a pupil enters the school. When a new pupil is being integrated into the education process, the school follows a proven procedure. The school management (mostly the principal or their deputy) take the necessary administrative steps, learning as much as they can about the child's learning history and based on his or her language competence, and enrolls the pupil in the year corresponding to his or her age, or one year lower (with consent of the child's legal representative). Research from abroad (see Appa, 2005; Cassity \& Gow, 2005, pp. 51-55) highlights the importance of accessing information about the child prior to his or her enrolment in a new school if better and more sensitive care is to be provided. The school investigated employed a special communication assistant to help the new learners and their parents adjust to the new school. The communication assistant had a high language proficiency and helped foreign parents register their child into the school and with other educational administration where the Czech language is necessary. The communication assistant is at hand mainly to the principal, helping with emails and written correspondence with parents, as the principal is not language qualified. It is interesting how the role of the communication assistant has transformed since it was introduced to the school in 2014. Originally the communication assistant was hired to help cope with an increased administrative load. The role changed when the number of foreign pupils began to increase and typically, their number does not increase only at the beginning of the school year, but also throughout the whole year. Other teachers usually do not use the communication assistant's linguistic abilities because they are not always available. "She's too far for us on the second floor, so we usually discuss translations with the psychologist or the English teachers."

As the school has a significant culturally diverse student base it appears to make an effort to foster maximum respect for cultural differences. For many children with different mother tongues, the primary goal is to learn the language, but experts also point out that it is essential to pay attention to other needs, including knowledge of one's own cultural identity (Sidhu \& Taylor, 2007, pp. 283-300). When we encounter a different culture, we can attribute different meanings to some behaviours. Intercultural sensitivity is of great importance when communicating with one another, which places demands on the reflection of possible misunderstandings arising from otherness and efforts to prevent them. The teachers are used to certain specifics that originate from certain religious traditions and as long as other participants of the educational process are not inconvenienced by this, they facilitate these differences (pursuant to agreement with the management). For instance, if a religious practice disallows some children from drawing or singing, the teachers assign them alternative activities. The teachers are mindful of national, ethnic and religious dif- 
50 ferences during normal teaching as well. In this context, we can suggest that there is a high level of intercultural sensitivity (Bennett, 2013) within the teaching workforce which is necessary for further communication in the classroom and avoidance of the misunderstanding. We heard pupils from different countries sing their respective folk songs during a lesson on local folklore. The children talk freely about the features of their original countries and culture. The school holds an annual running contest in which pupils of different nationalities race each other around the school. Otherness is perceived as a natural fact as a teacher says: "It's so varied here; we have a Roma, an African, an American, Argentinian, Indian, etc. Nobody cares if there is a Roma kid sitting here or not. No one's bothered." It may seem that reinforcing an individual's own ethnic or religious identity might clash with the main goal of the school - for example to emancipate the individual and empower him or her toward responsible behaviour. However, in this context the idea of identity has two facets. This approach is in keeping with contemporary social and developmental theories (Erikson \& Erikson, 1997; Feuerstein, Feuerstein, \& Falik, 2010). Recognising and accepting one's own identity is a prerequisite for constructing a positive and anxiety-free relationship towards the identities of others, which applies to intimate partner relationships and identities of broader groups alike. In the broadest terms for the whole of society human, universal rights for all are what matters most, and one pathway towards gaining this might be having a good knowledge of one's own identity. This makes it possible for each of us to properly understand what makes us different and what may provoke criticism from others and make them see us as less equal. "The greatest good [gained from knowing one's identity] is not the development and respect for a special group culture, but non-discrimination, equal rights, truly equal opportunities" (Barša, 2011, p. 104).

The contact between teachers and parents is intensive, but also governed by certain rules. At the primary level (age 6 to 11) teachers encounter parents on an informal basis almost daily when the children arrive to or leave the classroom and have an opportunity to discuss needs individually. When necessary, pupils take home written messages for parents in their journals or notebooks in an appropriate language. Parents are invited to parent/teacher meetings and in some cases to private consultations, but always by invitation or appointment. An interviewee's experience suggests, and the international research supports (Epstein, 2018, pp. 397-406), that the children of parents who communicate with the school regularly and actively, tend to perform better. "Some parents are proactive, they want to know, and then you can see that they really work on it with the child. They want to know if there is a problem, what sort of problem it is, and then try to remedy it." We consider this observation to be crucial because it is helpful for teachers as well. The knowledge that frequent communication with parents has a direct benefit for the child helps them overcome awkward moments of misunderstanding that occasionally arise with some parents.

However, during observations at the school we were informed that any unannounced visit from parents presents a security problem as in common in all Czech 
schools. Families immigrating to the Czech Republic from a different country often have a radically different experience with schooling, as illustrated by an interviewed teacher "it can be difficult talking to some children or parents; some have a completely different idea of some things, like coming to school prepared. (...) The parents must trust the teacher." The school needs to step forward and involve the parents in the functioning of the school. Teachers and the management have several means available (consultations, extracurricular events, parent/teacher meetings etc.) and given the local cultural customs, this should not present any cultural barrier. Hek (2005, pp. 157-171) states that if parents feel welcome in the school, it will positively affect the learners and improve their performance as well.

The school also holds community events for pupils and their parents several times a year outside of the regular teaching day. However, these events do not always fulfil their purpose, i.e. to bring all parents together. Sometimes only one of the ethnic groups from the school attends the events, or parents form groups according to their native language during the event. "Czech parents often just drop off their children and leave." For instance, at the last event held by the school (Halloween), Indian parents formed their own temporary community and communicated only among themselves.

\subsection{Communication as interactions amongst microsystem, mesosystem and macrosystem}

The second theme observes the means of communication both within the school and outside it and describes the trans-mesosystemic links that affect the school. These include relations with institutions or specific means of communication between mesosystems in the school (e.g. teachers, parents, class, language communities, etc.).

The teachers do not want the public to see their school as a school for foreigners. They believe such "pigeonholing" would provoke undesirable public opinion and Czech parents would stop registering their children in the school, preventing the learners with a different first language from hearing natively-spoken Czech, which the teachers stated that they rely on the Czech children for. "We want to be a school for Czechs that can teach foreigners as well." The teachers and the school counsellor claim that "an easy to manage" number of learners with a different first language is $25-30 \%$. However, the principal stated: "I'd like to stick to fifty percent, but it's true that two thirds are coming here from different parts of the city." It appears that principals of other schools in the city, as well as other non-Czech parents, want to send their existing pupils or children to the school due to the school's reputation. They are asking for children to be enrolled even if language isn't a barrier and instead it might be children who are merely encountering initial study problems, which tend to stem from behavioural issues, adjusting to the new environment and problems with the learning process. The school's principal has to accept these applicants, as if there is capacity in the school, they cannot legally turn them down. 
52 Teaching at this school is without a doubt very difficult. However, teachers can rely on the support of their colleagues. "Luckily, at least we who teach grades one to five (I can't speak for the rest, I don't know all the details), have a great team here, so we can always get help or advice." The school management works hard to build good relationships with and within the staff, which also affects the hiring of new employees, who have to fit in well with the others. Their financial motivation can also be increased by means of the many projects the school is involved in. However, this also means that the teachers have to cope with a larger administrative load. The principal gives all of the teachers enough freedom and has confidence in their teaching skills. They do not stand in the way of their using alternative methods (e.g. techniques of the Dalton plan), every teacher chooses the classroom layout for their lessons, they have no trouble obtaining funds for additional training, etc. Their job satisfaction and contentment can also be seen in the fact that virtually none of them resign their position, with teachers only leaving the school when they retire or start maternity leave. Staff fluctuations are generally very low there.

The teaching is made easier when the children of foreigners attend Czech preschool. In 2018 the school also organised a preliminary class, in which there were 6 learners with a different first language out of a total of 15. Primary-level teachers mentioned the benefit of preschool or the preliminary year on several occasions, however, most children arrive throughout the year from a primary school in a different country.

Another mesosystem that interacts with the school consists of secondary schools and the system of admissions. The teachers and the school psychologist have a tendency to recommend less difficult fields and caution the pupils against studying at gymnasiums (academic-oriented secondary schools), which they defend by referring to language barriers in academic terminology (this will be discussed in more detail in the third theme).

The school's mesosystem contains a number of interlinked microsystems, which make up a fluid whole. We can illustrate this fluidity using the example of a newly arriving pupil and their integration in the class. We understand integration in terms of Berry's (2006, pp. 27-42) adaptation strategies; i.e. as an ideal way of fitting into the host society, in which the minority retains its original identity while simultaneously adopting the identity of the host culture. According to Montgomery (1996, pp. 679-702), the psychological and social adaptation of children with a different first language is influenced by the age of the child, size of the town where the family has settled, any traumas the child may have suffered and their level of education. According to an interviewed teacher when a new pupil arrives, the mutual adjustment between them and the rest of the class, combined with the family environment, is critical. Knowledge of the curriculum comes last. The socialisation of the newly arrived child is therefore superior to all other learning goals. "If there's anyone with the same native language, they can surely be a kind of guide at the beginning ..." The positive influence of peer mentoring programmes ${ }^{9}$ and the preparation of the class

9 Which means the support of the experienced classmate in the beginning of the school attendance. 
team for the arrival of a new classmate is also evidenced by other authors (MacCullum,

2009 , pp. 3-4). Taking into account the individuality of each child, integration into the school team must take place in the context of all the specifics of the child, family and school. Only after all circumstances have been taken into account can we speak of achieving a homeostatic balance.

\subsection{The field of mutual understanding in relation to operating languages}

In this ethnically, religiously and nationally diverse school we noticed several operating languages used for communication - Czech, English, Ukrainian and Russian. These languages are switched according to situation. For instance, a teacher tries to teach in Czech, but if a learner fails to grasp a key piece of instruction even after several repetitions, she will briefly switch to English and then returns back to Czech. Most of the time, the teachers use Czech to speak with the children, but when communicating with parents, they need to find another common language. Not only does it emerge where the other languages overlap, but it also puts greater emphasis on the non-verbal aspect and the aspect of codified rules and behaviours that ensue. It has also been shown that in the case of transition from one operating language to another, other environmental features that facilitate understanding become more critical.

We observed especially that younger children can easily establish social contact in spite of the lack of a common verbal language. Their openness and spontaneity is much more effective. One of teachers put it: "They're friends, even when they can't understand each other yet, they're just friends. You'd have to see it. They play games like normal during the break, like 'pairs' and such." We noticed that the more experienced teachers speak in a very calm and slow voice, annunciating clearly and trying to be a good speech model for their learners. They also explain the meaning of many words, concrete or abstract, repeating them several times in several ways to improve the chances of understanding as much as possible. One of the teachers commented on the importance of rules: "Most important is probably to always try to find common language. And I don't mean language for talking. If you want the children to be in a calm space, there must be rules, dignity, discipline ... And then, when there's a pleasant positive atmosphere, where the children follow the rules, you can start teaching ... The parents must have trust that the teachers know what they are doing ..." Basic agreement on rules to observe can prevent many conflicts caused by misunderstandings that may occur when communication takes place in several operating languages. This is how the basic core (non-verbal and paralinguistic components and an emphasis on common rules) is formed and effectively takes over the functions of an operating language. The individual languages (Czech, English, Ukrainian ...) appear to be essential facets of something more primary - the field of mutual understanding. 
54 The task of this school is to develop language skills mainly in Czech. Research shows (Cummins, 1984, 2000) that people use two types of language at school: communication language (for everyday conversation during breaks, in changing rooms, during lunch, group work, etc.) and academic language (understanding terminology, sorting information, reading textbooks, writing assignments, taking notes, testing). Both these languages have their rules and specifics. Communication language is often based on the context of the situation, is less grammatically complex, and is therefore easier to master. The counsellor who is in charge of solving educational problems noted that "during breaks our children speak (...) what we call breaktime Czech". While important for successfully passing examination at various levels, the ability to read complex texts that feature unknown cultural details and use academic terminology, is difficult to acquire for learners with a different mother tongue. Generally speaking, children who are learning Czech as a second language, can hold a fluent conversation after two to three years of study, depending on how different their first language is (other theories say six months to two years). However, it takes them five to seven years, even ten in some cases, before they have caught up with their schoolmates in academic language (Cummins, 2000). It can be assumed that in the school discussed here, given its high degree of language heterogeneity and the fact that pupils with a different first language make up almost two thirds of all children, acquiring Czech by osmosis will take longer. We observed that the pupils often seek friends with the same mother tongue. When the learners achieve a sufficient level of academic language, they often leave the school, mostly because of a long commute, and start attending a school nearer their home. However, some remain because of the ties they made and because they are familiar with the system. "I call them 'acting as Czechs', those who stay and speak well. Many of the foreign children look up to those who learned better and faster."

When differentiating between communication and academic language it is necessary to mention the complications that may arise in later years. Children who seem well adapted, i.e. with a good command of the communication language acquired during preschool or early years of school, may encounter difficulties with academic language, which becomes more difficult when the learning content advances during later school years. Proficiency in academic language strongly limits the choice of secondary school. Even during professional aptitude tests administered by the school psychologist, many of the children score poorly in verbal tasks (their results correspond to reduced IQ). These results are part of the reason why it is recommended for the children to pursue less difficult secondary schools, mostly vocational schools.

Mastery of Czech thus strongly determines the pupils' future education career. Both the teachers and management are well aware of this. The school offers several ways of boosting progress in the language. The teachers are also aware of the limitations of the existing system, "We're having Czech for the whole class and it is actually a foreign language for the kids; often even English isn't as foreign as Czech, which we would need to split into groups." This claim is logical as there can 
be learners of several levels of language proficiency present in the lesson, making its preparation and execution more difficult. At present, the school offers the following assistance to learners with a different first language:

1. Group courses of Czech for complete beginners (A0-A1 proficiency). They take place in the morning, which means the learner misses certain regular lessons (typically subjects that require a high level of comprehension, which the child may still lack) a separate model. (Eurydice, 2004)

2. Group courses of Czech taking place in the afternoon in collaboration with the Regional Centre for the Support of the Integration of Foreigners.

3. One-to-one tutoring in subjects with which the learners need help (in learners with a different first language, this means lessons of (zech) in collaboration with City Hall.

Although the pupils receive intensive language support, it is hindered by some limitations as a result of the way the macrosystem is set up. For instance, there is the inconvenient fact that the morning courses are funded by the Ministry on a calendar-year basis and do not follow the school year. This means that every year the management has no guarantee of knowing whether their grant application will be approved and therefore the courses are not taught in January and February due to a lack of funding.

\section{Discussion and conclusion}

Our findings relate to one particular school, which in the last ten years has become a school in which the number of pupils from families with a migrant background predominates. As a result, a school that wanted to be inclusive became a school where the importance of Czech as the main operational language is significantly weakened. This places increased demands on actors and forces them to create a more sophisticated environment in which mutual understanding can be achieved despite all obstacles. To understand this correctly, we introduced the concept of mutual understanding and based on this concept and the 17 hypotheses of Bronfenbrenner, we defined three themes that became the basis for the framework analysis.

In the first theme, while discussing communication as the central value of the school, we identified certain important topics. The unusual position of the communication assistant helps to manage the process of admitting new children to the school throughout the year. Being respectful and sensitive to cultural and religious differences encourages the children to form their own identities and the high level of intercultural sensitivity of the teachers supports a positive class and school climate. This data mirrors the tone of other foreign research dealing with cultural sensitivity (Bennett, 2009, pp. 2-7). The school understands that it is important to communicate with parents on a regular basis if the children are to have good results. The school offers communication in several formats. There are clear definitions of what the parents must not do (e.g. enter the school without appointment) and these rules are understood. 
In relation to Bronfenbrenner's approach and the notion of trans-systemic linkage (theme two), it is a basic tenet of the school that it has transformed from a traditional school into one that can accept the children of foreigners. The current state of the mesosystem - $65 \%$ of children of foreign nationality - has received strong support from the policies of the macrosystem (a decision of the Department of Education of the municipality; the Ministry and its grant strategy). However, the participants do not view this situation positively. They want to be a school for everyone, while retaining a good ability to work with learners with a different first language. They consider the ideal percentage of foreign children to be $25-30 \%$. The school boasts strong interpersonal support, both among the teachers themselves and it is also inherent within the personnel policy - it is important that the teachers feel good and their independence, initiative and creativity is rewarded. The teaching team is stable. The school is characterized by an increased awareness of and care for the quality of linkage between the following mesosystems - transition from preschool to school, and from primary school to secondary school. When a new child arrives in the school, there is a strong emphasis on the smooth progress of the adaptation process, taking into account all the cultural and religious specifics of the child's family.

Theme three explored the field of mutual understanding in relation to operating languages and there are several operating languages in the school. The high percentage of foreign pupils allows for a considerable degree of support in learning Czech by various methods, however, it slows down the process of spontaneous acquisition as the school lacks enough native speakers in peer groups. In the situation when only every third child is a Czech language native speaker there is limit to the number of occasions the students can hear and speak the language of their education.

Communication difficulties highlight the importance of non-verbal and paralinguistic means and of following simple shared rules which facilitate comprehension regardless of mother tongue. It is these aspects that are part of the field of mutual understanding. A good command of the communication language does not automatically mean good results in the academic language (UNESCO, 2016) and this complicates the educational trajectory of learners with a different first language.

The results of our case study show that centralizing children from a migratory background into one school brings many problems and does not correspond with the modern concept of inclusive education. Other schools need to be more closely involved in the whole system of education of foreign pupils, where children from large cities, in particular, could study in the "catchment area". These schools, understandably hesitant to admit foreigners, need intensive support from their founders, not just material and financial, but also ideological and methodological (sharing practice). In this context, the school under investigation can help by providing background for practice as well as by sharing experiences with other schools. Therefore, communication and interconnection between the exosystem or macrosystem, on the one hand, and the mesosystem, on the other, are crucial for the successful building of an inclusive environment. 


\section{Acknowledgements}

At this point, we would like to thank both reviewers. Their critical and detailed comments help us to detect insufficiencies of the original text.

\section{References}

Appa, V. A. (2005). Study on how asylum seekers and refugees access education in four local authorities in England. London: National Children's Bureau.

Barša, P. (2011). Orientálcova vzpoura [The Oriental rebellion]. Prague: Dokořán.

Bennett, M. J. (2009). Defining, measuring, and facilitating intercultural learning: a conceptual introduction to the Intercultural Education double supplement. Intercultural Education, 20(1), 1-13.

Bennett, M. (2013). Basic concepts of intercultural communication: Paradigms, principles, \& practices. Boston: Intercultural Press.

Berry, J. W. (2006). Contexts of acculturation. In D. L. Sam \& J. W. Berry (Eds.), The Cambridge handbook of acculturation psychology (pp. 27-42). New York: Cambridge University Press.

Bronfenbrenner, U. (1979). The ecology of human development. Experiments by nature and design. Cambridge (MA), London: Harvard University Press.

Cassity, E., \& Gow, G. (2005). Making up for lost time: The experiences of Southern Sudanese young refugees in high schools. Youth Studies Australia, 24(3), 51-55.

Český statistický úrad (2019). Data - počty cizinců. Available from: https://www.czso.cz /csu/cizinci/4-ciz_pocet_cizincu\#cr

Cummins, J. (1984). Bilingualism and special education: Issues in assessment and pedagogy. San Diego: College Hill.

Cummins, J. (2000). Language, power and pedagogy: Bilingual children in the crossfire. Clevedon: Multilingual Matters.

Damasio, A. (2018). The Strange order of things: Life, feeling, and the making of cultures. New York: Pantheon Books.

Denzin, N. K., \& Lincoln, Y. S. (2003). Handbook of qualitative research. London: Sage.

Dewey, J. (1939). Logic: The theory of inquiry. New York: Henry Holt.

Dewey, J. (1958). Experience and nature. New York: Dover Publicating.

Dewey, J., \& Bentley, Arthur F. (1949). Knowing and the known. Boston: Beacon Press.

Dockett, S., Perry, B., \& Kearney, E. (2012). Family transitions as children start school. Family Matters, 90, 57-67.

Erikson, E. H., \& Erikson, J. M. (1997). Life cycle completed. Extended version with new chapters on ninth stage of development. New York: W. W. Norton.

EURYDICE (2004). Integrating Immigrant Children into Schools in Europe. Brussel: Euridyce.

Epstein, J. L. (2018). School, family, and community partnerships in teachers' professional work. Journal of Education for Teaching, 44(3), 397-406.

Feuerstein, R., Feuerstein, R. S., \& Falik, L. H. (2010). Beyond smarter - mediated learning and the brain's capacity for change. New York: Teachers College Press.

Hamilton, R. J., \& Moore, D. (2004). Educational interventions for refugee children: Theoretical perspectives and implementing best practice. London: Routledge Falmer.

Hayes, N., O’Toole, L., \& Halpenny, A. M. (2017). A Guide for practitioners and students in early years education. London: Routledge.

Hek, R. (2005). The role of education in the settlement of young refugees in the UK: The experience of young refugees. Practice, 17(3), 157-171.

Johnson, M. (2007). The meaning of the body. Chicago: The University of Chicago Press.

Lakoff, G. (1987). Women, fire, and dangerous things. Chicago: The University of Chicago Press. 
58 MacCullum, D. (2009). Newcomer orientation week in Ontario high schools. INSCAN (International Settlement Canada), 23(2), 3-4.

Montgomery J. R. (1996). Components of refugee adaptation. International Migration Review, 30(3), 679-702.

Noiriel, G. (2012). Úvod do historické sociologie [Introduction to historical sociology]. Prague: Slon.

Sidhu, R., \& Taylor S. (2007). Educational provision for refugee youth in Australia: Left to chance? Journal of Sociology, 43(3), 283-300.

Srivastava, A., \& Thomson, S. B. (2009). Framework analysis: A qualitative methodology for applied policy research. JOAAG, 4(2), 72-79.

Super, Ch. M., \& Harkness, S. (2002). Culture structures the environment for development. Human Development, 45(4), 270-274.

Švec, V., Nehyba, J., Svojanovský, P., et al. (2017). Becoming a teacher: The dance between tacit and explicit knowledge. Brno: MUNIPress.

UNESCO (2016). If you don't understand, how can you learn? Policy Paper, 24(1), 1-9.

Watzlawick, P. B., Beavin, J., \& Jackson, D. D. (1962). Pragmatics of human communication: A study of interactional patterns, pathologies, and paradoxes. New York: W. W. Norton.

Yin, R. K. (2012). Case study methods. In H. Cooper, P. M. Camic, D. L. Long, A. T. Panter, D. Rindskopf, \& K. J. Sher (Eds.). APA handbook of research methods in psychology, Vol. 2. Research designs: Quantitative, qualitative, neuropsychological, and biological (pp. 141-155). Washington: American Psychological Association.

PhDr. Denisa Denglerová, Ph.D. Masaryk University, Faculty of Education

Poříći 7, 60300 Brno, Czechia denglerova@ped.muni.cz

Mgr. Martina Kurowski, Ph.D. Masaryk University, Faculty of Education Poříči 7, 60300 Brno, Czechia kurowski@ped.muni.cz

doc. Mgr. Radim Šíp, Ph.D. Masaryk University, Faculty of Education

Poříčí 7, 60300 Brno, Czechia sip@ped.muni.cz 